\title{
Hedgefondsen Prestaties uit het verleden bieden verwachtingen voor de toekomst
}

\section{Jenke ter Horst en Marno Verbeek}

SAMENVATTING De populariteit van hedgefondsen is aan het einde van de jaren negentig sterk toegenomen. De voornaamste reden hiervoor is dat hedgefondsen zowel in stijgende als dalende markten een positief rendement proberen te realiseren. Dit geeft interessante diversificatiemogelijkheden voor bijvoorbeeld pensioenfondsen, die het risico van hun bestaande beleggingsportefeuilles weten te reduceren door gedeeltelijk te beleggen in hedgefondsen. In dit artikel onderzoeken we de vraag of er sprake is van persistentie in de prestaties van hedgefondsen. In tegenstelling tot wat vaak bij traditionele beleggingsfondsen wordt gevonden, blijkt er volgens ons onderzoek in de periode 1994-2000 bij hedgefondsen wel sprake te zijn van persistentie. Een strategie waarbij in de beste $10 \%$ hedgefondsen van het afgelopen kwartaal wordt belegd, zou tot een jaarlijks rendement hebben geleid dat $12 \%$ hoger is in vergelijking met de slechtste $10 \%$ hedgefondsen van het afgelopen kwartaal. Dit impliceert dat prestaties uit het verleden een belangrijke leidraad kunnen zijn bij de selectie van hedgefondsen, en dat dit tot een beter beleggingsrendement van bijvoorbeeld pensioenfondsen kan leiden.

\section{Inleiding}

Hoewel iedereen er inmiddels wel van is doordrongen dat in het verleden behaalde resultaten geen garantie bieden voor de toekomst, blijkt uit empirisch onder-

Dr. J. ter Horst is universitair hoofddocent financiering en belegging in het departement financiering van de Universiteit van Tilburg en senior onderzoeker bij NETSPAR.

Prof. Dr. M. Verbeek is hoogleraar ondernemingsfinanciering aan RSM Erasmus University en het Econometrisch Instituut van de Erasmus Universiteit Rotterdam en senior onderzoeker bij NETSPAR. zoek dat particuliere beleggers zich bij de keuze van beleggingsfondsen voor een groot deel laten leiden door de prestaties uit het verleden (Sirri en Tufano, 1998). Beleggers investeren aanzienlijk meer in fondsen die het de afgelopen tijd goed hebben gedaan in de verwachting dat deze fondsen in de nabije toekomst ook blijven presteren. Deze strategie is opmerkelijk omdat er weinig bewijs is voor de hypothese dat het volgen van een actieve selectiestrategie met betrekking tot beleggingsfondsen tot hogere verwachte rendementen leidt. Met andere woorden, er is geen tot weinig bewijs voor persistentie in de prestaties van beleggingsfondsen (Carhart, 1997). Mogelijk is de afwezigheid van persistentie zelfs (mede) het gevolg van actieve selectie door beleggers op zoek naar een superieur beleggingsresultaat, waardoor elke voorspelbaarheid - in lijn met de efficiënte markttheorie - wordt weggeconcurreerd (Berk en Green, 2004). In dit artikel beschouwen we de vraag of er bij hedgefondsen wel sprake is van persistentie. Beleggingen in hedgefondsen kenmerken zich onder meer door hun beperkte liquiditeit, waardoor er reden bestaat andere resultaten te verwachten dan voor traditionele beleggingsfondsen ${ }^{1}$.

Hedgefondsen vormen een relatief nieuwe beleggingscategorie die erg populair is geworden sinds het eind van de jaren negentig. Pensioenfondsen als het ABP hebben inmiddels vele honderden miljoenen belegd in hedgefondsen. Een hedgefonds lijkt veel op een traditioneel beleggingsfonds, maar is veel flexibeler in de soorten activa dat het aanhoudt, en de posities die het inneemt. Hedgefondsen investeren bijvoorbeeld volop in derivaten, nemen short posities in, of doen aan leverage. Allemaal mogelijkheden die bij traditionele fondsen zeer ongebruikelijk zijn, of zelfs niet toegestaan volgens de geldende richtlijnen. Een goede definitie voor hedgefondsen ontbreekt, maar het belangrijkste kenmerk is dat ze zich nauwelijks aan de richtlijnen voor traditionele beleggings- 
fondsen hoeven te houden. Ze zijn bijvoorbeeld niet verplicht hun prestaties en gevolgde strategie te rapporteren in de vorm van een jaarverslag. Doordat de meeste hedgefondsen streven naar een hoog absoluut rendement, onafhankelijk van de marktsituatie, bieden ze potentieel interessante diversificatiemogelijkheden ten opzichte van bestaande beleggingsportefeuilles.

In tegenstelling tot wat gewoonlijk bij traditionele beleggingsfondsen wordt gevonden (zie onder meer Carhart, 1997; Bollen en Busse, 2004), blijkt er volgens ons onderzoek bij hedgefondsen wel sprake te zijn van positieve persistentie. Dit betekent dat hedgefondsen die in het recente verleden een bovengemiddelde prestatie hebben laten zien, naar verwachting ook in de komende periode weer bovengemiddeld zullen presteren. Gedurende de onderzochte periode 1994-2000 zou een strategie waarbij in de $10 \%$ beste fondsen van het afgelopen kwartaal wordt belegd tot een gemiddeld jaarlijks rendement hebben geleid dat $12 \%$ hoger is in vergelijking met de slechtste hedgefondsen van het afgelopen kwartaal.

De opbouw van dit artikel is verder als volgt. In paragraaf 2 zullen we de historische ontwikkeling en maatschappelijke rol van hedgefondsen toelichten. In paragraaf 3 wordt een aantal specifieke kenmerken van hedgefondsen nader besproken. Vervolgens geven we in paragraaf 4 wat meer details van de door ons onderzochte groep hedgefondsen, waarna we in paragraaf 5 de resultaten van onze empirische analyse bespreken. We sluiten af met een aantal concluderende opmerkingen in paragraaf 6 .

\section{Historische ontwikkeling en maatschappelijke rol hedgefondsen}

In de jaren vijftig en zestig ontwikkelde en beheerde Alfred W. Jones het eerste hedgefonds. Jones was ervan overtuigd dat hij onder- of overgewaardeerde aandelen kon selecteren, maar dat hij niet in staat was de richting van de markt te voorspellen. De strategie van dit eerste hedgefonds was om een min of meer marktneutrale positie in te nemen door aandelen die ondergewaardeerd zijn te kopen, en om short te gaan in aandelen die overgewaardeerd zijn. Om extra ondergewaardeerde aandelen te kopen, werd er soms gebruikgemaakt van leverage door de opbrengsten van de short positie te gebruiken voor de aankoop. Het fonds was zeer succesvol en wist gevestigde beleggingsfondsen te verslaan met rendementen van $40 \%$ tot $80 \%$ over een periode van vijf tot tien jaar. Deze prestaties brachten hedgefondsen onder de aandacht van een breder publiek, en deed ook het aanbod van deze fondsen stijgen. Met het grotere aanbod groeide ook de verscheidenheid in beleggingsstijlen van de hedgefondsen. De short posities werden veelal achterwege gelaten aan het eind van de jaren zestig, maar dit werd afgestraft gedurende het begin van de jaren zeventig. De markt daalde sterk en dit leidde tot enorme verliezen bij hedgefondsen. Het gevolg was dat een groot deel van deze fondsen verdween, waarna de belangstelling van het publiek sterk afnam.

Aan het eind van de jaren tachtig en het begin van de jaren negentig kwamen hedgefondsen opnieuw in de belangstelling door de zeer hoge rendementen van onder andere het 'Quantum Investment Fund' van George Soros. Dit fonds realiseerde een enorme winst van ongeveer 1 miljard dollar ten gevolge van het feit dat het Britse Pond het Europees Monetair Systeem moest verlaten. Of het hedgefonds verantwoordelijk was voor deze gebeurtenis, blijft een onbeantwoorde vraag, maar het heeft er zeker toe bijgedragen. Mede aangewakkerd door de gebeurtenissen rond de Aziatische crisis eind jaren negentig, wordt in de populaire pers regelmatig gemeld dat hedgefondsen financiële instabiliteit veroorzaken en dat ze de markten minder efficiënt maken. Hiervoor is weinig bewijs en een tegenargument is dat ze juist de efficiëntie verbeteren door nauwkeurig de markten af te tasten voor mogelijke arbitragemogelijkheden.

Dat hedgefondsen niet risicoloos zijn (en dat de term 'hedge' wellicht misleidend is), bleek duidelijk bij het faillissement van Long Term Capital Management (LTCM). Dit hedgefonds was mede opgericht door twee Nobelprijswinnaars in de economie (Robert Merton en Myron Scholes). Het buitensporige gebruik van leverage en de grootte van de posities die het fonds innam op verschillende markten, deed de kapitaalmarkten eind jaren negentig op hun grondvesten schudden. Ook het Quantum Fund van Soros boekte in deze periode grote verliezen. Vooralsnog zijn dit uitzonderingen gebleken, en is de belangstelling om in hedgefondsen te beleggen alleen maar toegenomen, mede doordat ze er gemiddeld in slagen in zowel op- als neergaande markten positieve rendementen te realiseren. Dit maakt ze vanuit diversificatieperspectief interessant omdat een uitbreiding van een portefeuille met een of meer hedgefondsen, het risico van de bestaande beleggingsportefeuilles aanzienlijk kan reduceren. Volgens een recente schatting zijn er momenteel ruim 6000 hedgefondsen actief, met een totaal belegd vermogen van meer dan 600 miljard dollar. 


\section{Specifieke kenmerken van hedgefondsen}

Hedgefondsen hebben een aantal specifieke kenmerken die we meestal niet bij traditionele beleggingsfondsen vinden. Naast de al eerder genoemde flexibiliteit in soorten activa, is er bij hedgefondsen vaak sprake van een zogenoemde 'lock-up'-periode, gedurende welke beleggers hun investering niet liquide kunnen maken. Deze beperking heeft als voordeel dat hedgefondsmanagers meer vrijheid hebben in het opzetten van illiquide posities, zonder de dreiging dat deze op korte termijn moeten worden afgesloten. Deze 'lock-up'-periode kan variëren van een kwartaal tot zelfs meer dan een jaar.

Een ander belangrijk verschil wordt gevormd door de beloningsstructuur van fondsmanagers. Bij traditionele beleggingsfondsen ontvangt de fondsmanager gewoonlijk een vast percentage van 1 à $2 \%$ van het belegde vermogen als vergoeding. Bij hedgefondsen is een deel van de beloning mede afhankelijk van de prestaties van de manager, de zogenoemde 'incentive fee'. Deze beloning kan variëren tussen de $10 \%$ en $50 \%$ van het rendement dat een hedgefonds behaalt boven het risicovrije rendement. Behaalt de manager dit niet, dan wordt er geen prestatiebeloning uitgekeerd. Bovendien zullen verliezen uit het verleden eerst moeten worden goedgemaakt, wat wordt aangeduid met de term 'high-water mark'-niveau. Gecombineerd met het feit dat veel hedgefondsen vereisen dat managers een deel van hun eigen vermogen in het fonds beleggen, levert dit een bijzondere incentivestructuur op waarbij de omvang van het belegde vermogen maar een beperkte rol speelt.

Niet iedereen kan beleggen in hedgefondsen. Voor Amerikaanse 'onshore'-fondsen is het bijvoorbeeld niet toegestaan meer dan 500 participanten te hebben, terwijl elk van deze deelnemers moet beschikken over voldoende kennis, ervaring, en vooral vermogen (veelal minimaal 1 miljoen dollar). De consequentie is dat deze hedgefondsen niet gemakkelijk toegankelijk zijn voor particuliere beleggers en kleine vermogensbeheerders. Gemakkelijker toegankelijk zijn de zogenaamde 'offshore'-fondsen, die veelal gevestigd zijn in belastingparadijzen zoals de Bermuda Eilanden. Deze hedgefondsen blijven in principe buiten de toezichtregels van financiële autoriteiten en de grens van 500 participanten geldt niet, hoewel andere beperkingen nog wel van toepassing kunnen zijn. Voor zowel onshore- als offshorefondsen geldt dat om buiten de toezichtregels van traditionele beleggingsfondsen te blijven, er niet actief geadverteerd mag worden. Om de drempel van het beleggen in hedgefondsen te ver- lagen, worden er steeds meer 'funds-of-funds' aangeboden, ook in Nederland ${ }^{2}$. Dit is niets anders dan een portefeuille van verschillende hedgefondsen, waarbij de tussenpartij de selectie doet uit het aanbod van onshore- en offshorefondsen. Vanuit diversificatieperspectief kan een dergelijk fund-of-funds interessant zijn, hoewel men wel wordt geconfronteerd met een dubbele heffingsstructuur, waarbij zowel de onderliggende hedgefondsen als de beheerder van het fundof-funds een deel van het resultaat afsnoepen.

\section{Steekproefgegevens}

In ons onderzoek beschouwen we de periode 1994-2000. We baseren ons op kwartaalgegevens van hedgefondsen die hun rendementen publiceren in Amerikaanse dollars, afkomstig uit de TASS-database ${ }^{3}$. In totaal observeren we 1797 hedgefondsen, waarvan er nog 1185 actief zijn in het eerste kwartaal van 2000. Gedurende de steekproefperiode verdwijnen er 612 fondsen. Dit komt neer op een uitvalpercentage van $8,6 \%$ per jaar en dat is aanzienlijk hoger dan bij de traditionele beleggingsfondsen waar ongeveer $4 \%$ van de fondsen verdwijnt. Van deze uitval is 5,2\% toe te wijzen aan liquidatie of opheffing van het betrokken hedgefonds. De rest verdwijnt omdat de fondsmanager niet langer zijn resultaten openbaar wil maken via TASS.

In tabel 1 presenteren we de gemiddelde jaarrendementen voor drie steekproeven van hedgefondsen en de S\&P 500-index. De eerste steekproef duiden we aan met 'alle fondsen' en betreft alle hedgefondsen die in de beschouwde periode bestaan hebben of nog steeds bestaan. De tweede steekproef bevat alleen fondsen die aan het einde van de onderzochte periode nog actief zijn, terwijl de derde steekproef alleen bestaat uit de fondsen die gedurende de steekproefperiode zijn geliquideerd. De groep 'alle fondsen' omvat dus zowel de geliquideerde als actieve fondsen en bevat bovendien de fondsen die vrijwillig niet meer rapporteren.

Uit tabel 1 blijkt dat geliquideerde fondsen gemiddeld aanzienlijk lagere rendementen hebben behaald dan niet-geliquideerde fondsen; 3,14\%, respectievelijk $15,79 \%$ per jaar. Duidelijk is dat het gemiddelde rendement van hedgefondsen wordt overschat wanneer men zich alleen baseert op de nog bestaande actieve fondsen. Deze laatste groep fondsen heeft een gemiddeld rendement van $15,79 \%$ over de periode 1994-2000, terwijl het gemiddelde rendement van de bestaande en verdwenen hedgefondsen samen $13,41 \%$ bedraagt. Deze overschatting van het gemid- 
Tabel 1. Gemiddelde jaarrendementen hedgefondsen en S\&P 500-index.

\begin{tabular}{|c|c|c|c|c|}
\hline Jaar & Alle fondsen & Actieve fondsen & Geliquideerde fondsen & S\&P 500 \\
\hline 1994 & $-0,14 \%$ & $0,95 \%$ & $-2,33 \%$ & $1,56 \%$ \\
\hline 1995 & $16,42 \%$ & $19,82 \%$ & $9,69 \%$ & $37,38 \%$ \\
\hline 1996 & $17,71 \%$ & $20,21 \%$ & $11,52 \%$ & $22,96 \%$ \\
\hline 1997 & $16,88 \%$ & $18,59 \%$ & $8,02 \%$ & $33,29 \%$ \\
\hline 1998 & $3,49 \%$ & $6,11 \%$ & $-6,86 \%$ & $28,52 \%$ \\
\hline 1999 & $26,11 \%$ & $29,08 \%$ & $-1,23 \%$ & $19,95 \%$ \\
\hline $2000 / 01$ & $6,00 \%$ & $6,30 \%$ & $-6,50 \%$ & $3,80 \%$ \\
\hline gemiddeld & $13,41 \%$ & $15,79 \%$ & $3,14 \%$ & $23,94 \%$ \\
\hline
\end{tabular}

delde rendement staat in de literatuur bekend als 'survivorship bias', en bedraagt voor onze steekproef $2,38 \%$. Opvallend is verder dat het gemiddelde hedgefonds een passieve index als de S\&P 500 niet weet te verslaan.

Bij het onderzoeken van de persistentie in de prestaties van beleggingsfondsen of hedgefondsen, is het belangrijk om rekening te houden met verdwenen fondsen over de beschouwde periode. De reden is simpel. Indien de kans op uitval negatief samenhangt met de prestaties uit het verleden, zal een analyse gebaseerd op uitsluitend de nog bestaande fondsen de gemiddelde prestaties van de fondsen overschatten. Er zijn immers relatief veel slecht presterende fondsen verdwenen. De resultaten in tabel 1 suggereren dat lagere rendementen de kans op liquidatie vergroten, en dit wordt inderdaad bevestigd door de formele analyse in Baquero, Ter Horst en Verbeek (2005). Andere factoren die de uitvalkansen negatief beïnvloeden, zijn de grootte van het fonds en de leeftijd (vanaf het derde jaar). De hoogte van de incentive fee' van de manager, en het feit dat een fonds 'onder water' is ${ }^{4}$ hebben een negatief effect op de overlevingskans.

\section{Geven resultaten uit het verleden een indicatie voor de toekomst?}

De vraag die we in dit artikel onderzoeken is in hoeverre de toekomstige prestaties van hedgefondsen te voorspellen zijn op basis van hun historische rendementen, dat wil zeggen, in hoeverre er sprake is van persistentie in de prestaties van hedgefondsen. Om dit te onderzoeken wordt de onderzoeksperiode (van bijvoorbeeld twee jaar) opgesplitst in twee subperioden: een selectieperiode en een evaluatieperiode. Voor beide perioden worden de prestaties bepaald van de beschikbare hedgefondsen. Op basis van de resultaten van de eerste periode wordt een indeling gemaakt in een aantal klassen. Uitgaande van een opdeling in tien groepen, bevat deciel 1 de $10 \%$ slechtste fondsen en deciel 10 de 10\% beste fondsen. Vervolgens bepalen we de gemiddelde prestaties over de tweede periode voor alle fondsen in een gegeven deciel. Ten slotte wordt deze analyse een aantal keren herhaald door de onderzoeksperiode op te schuiven binnen de steekproefperiode, waarna het gemiddelde wordt genomen. Om het persistentiepatroon zo zuiver mogelijk te schatten, nemen we de verdwenen en geliquideerde fondsen mee tot het kwartaal dat ze uit de steekproef verdwijnen. Dit is de oplossing die in de meeste recente studies wordt gevolgd ${ }^{5}$. Echter, in Ter Horst, Nijman en Verbeek (2001) is aangetoond dat dit nog niet tot een zuiver geschat persistentiepatroon zal leiden. Dit wordt veroorzaakt door het feit dat een persistentieanalyse oplegt dat fondsen over een aantal achtereenvolgende kwartalen rendementen rapporteren. Wanneer hier in de analyse geen rekening mee wordt gehouden, kan dit leiden tot serieuze vertekeningen (zie ook Verbeek, 2002).

Om dit te begrijpen is het van belang dat hedgefondsen niet alleen zeer verschillende strategieën volgen, maar ook zeer uiteenlopende maten van risico kennen. Fondsen met een hoog risico hebben een relatief grote kans om een gerealiseerd rendement te hebben dat ver van hun gemiddelde rendement ligt, zowel erboven als eronder. Met andere woorden, fondsen met een hoge volatiliteit in de eerste periode zullen met een grotere kans terechtkomen in een van de extreme decielen (met name 1 en 10), terwijl fondsen met een lage volatiliteit relatief vaker in de middelste decielen te vinden zullen zijn. Vooralsnog is dit geen probleem, zolang we maar beseffen dat de relatieve positie van een fonds in de eerste periode iets te maken heeft met het specifieke risico dat het fonds neemt. 
Laten we nu de tweede periode in ogenschouw nemen. Binnen elk deciel nemen we dan het gemiddelde rendement. Dit gemiddelde is een maat voor de verwachte prestaties over de komende periode, gegeven dat een fonds in de eerste periode bijvoorbeeld bij de beste $10 \%$ of slechtste $10 \%$ hoort. Stel nu dat fondsen die relatief slecht scoren met een grotere kans verdwijnen dan de relatief goede fondsen. Deze veronderstelling wordt door empirisch onderzoek ondersteund. Doordat de slechtst presterende fondsen gemiddeld genomen een hoog risico kennen, betekent dit dat fondsen die in de evaluatieperiode niet zijn verdwenen, gemiddeld genomen betere prestaties laten zien. Dit effect is het grootst voor fondsen die een hoog risico kennen. Immers, hoe groter de onzekerheid, hoe meer de staart van de rendementsverdeling wordt afgekapt door de uitval. Achteraf, als we de prestaties in de evaluatieperiode beschouwen - noodzakelijkerwijs alleen voor de fondsen die nog bestaan - betekent dit dat fondsen in de extreme decielen gemiddeld genomen betere prestaties kennen. In de afwezigheid van enige persistentie leidt dit tot een schijnverband dat uitsluitend te wijten is aan de selectieve uitval en niets te maken heeft met enig positief verband tussen de prestaties van de fondsen in verschillende deelperioden. Iets algemener veroorzaken verschillen in risico opwaartse vertekeningen in de gemiddelde rendementen in de evaluatieperiode, met name voor de extreme decielen.

Indien we hiervoor willen corrigeren, hebben we informatie nodig over de manier waarop de fondsen uit de steekproef verdwijnen en hoe dit samenhangt met de al of niet waargenomen rendementen. Onder milde veronderstellingen (zie Ter Horst, Nijman en Verbeek, 2001), kunnen op basis van het empirische liquidatieproces eenvoudig gewichten worden bepaald. $\mathrm{Bij}$ de analyse wordt vervolgens de gebruikelijke schattingsmethode toegepast, waarbij de waarnemingen van elk fonds een verschillend gewicht krijgen ${ }^{6}$. Een dergelijke gewogen analyse zorgt ervoor dat het schijnpatroon veroorzaakt door 'look-ahead bias' verdwijnt.

Voor de onderzochte groep hedgefondsen presenteren we in figuur 1 het persistentiepatroon op kwartaalbasis, waarbij zowel de selectie- als evaluatieperiode gelijk is aan een kwartaal. In ieder kwartaal is een rangorde gemaakt van alle hedgefondsen, waarna de fondsen worden opgesplitst in decielen. In het aansluitende kwartaal evalueren we vervolgens de prestaties van deze decielen door het gemiddelde rendement te bepalen, gecorrigeerd voor 'look-ahead bias'. Deze procedure herhalen we tot het einde van de

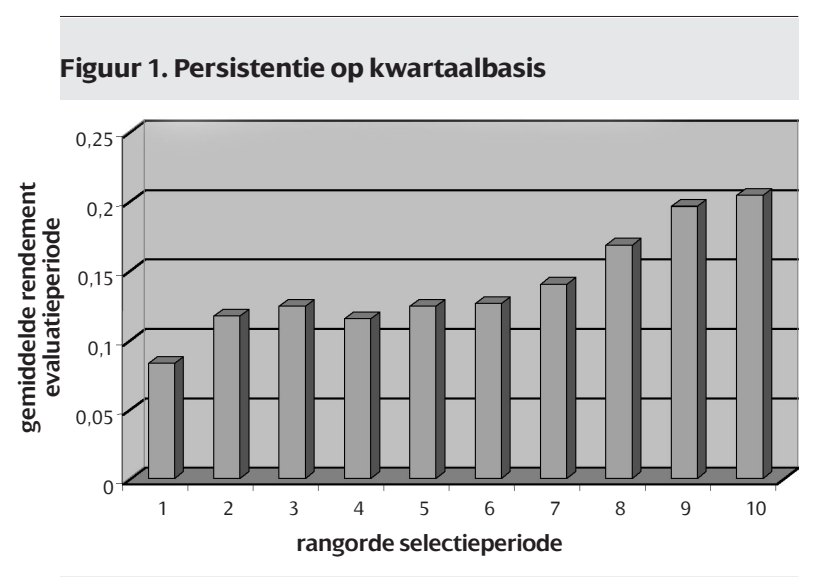

steekproefperiode, en dit geeft ons in totaal 22 waarnemingen.

Figuur 1 laat een duidelijk patroon zien. De beste vier decielen ( 7 tot en met 10) presenteren ook een kwartaal later nog bovengemiddeld. Het topdeciel heeft een verwacht rendement van ruim $20 \%$ op jaarbasis, tegenover $8 \%$ voor het slechtste deciel. Ook andere studies rapporteren persistentie op kwartaalbasis, maar houden geen rekening met de overlevingseffecten inherent aan de methodologie zoals eerder beschreven.

Een vergelijkbare analyse hebben we uitgevoerd op jaarbasis, waarbij zowel de selectieperiode als de evaluatieperiode gelijk is aan een jaar. Deze perioden worden steeds een kwartaal opgeschoven. Het resulterende patroon wordt weergegeven in figuur 2, die wederom een duidelijk patroon laat zien. Vooral de beste drie decielen ( 8 tot en met 10) laten in het daaropvolgende jaar een bovengemiddeld rendement zien. De fondsen die in het afgelopen jaar het beste hebben gepresteerd (deciel 10) hebben een verwacht rendement van ruim $20 \%$ op jaarbasis, terwijl de fondsen die het zwakst waren in het afgelopen jaar (deciel 1) slechts een verwacht rendement hebben van $12 \%$ op jaarbasis. Wanneer men niet voor lookahead bias' zou corrigeren, dan zou het verwachte rendement voor deciel 1 uitkomen op bijna 16\%. Dat is een overschatting van bijna $4 \%$ (statistisch significant), en dat duidt erop dat correctie voor overlevingseffecten bij persistentiestudies noodzakelijk is ${ }^{7}$. Een mogelijke verklaring voor het feit dat bij hedgefondsen, in tegenstelling tot traditionele beleggingsfondsen, wel een positief verband wordt gevonden tussen prestaties uit heden en verleden, is dat de liquiditeit van hedgefondsen beperkt is. Bij traditionele beleggingsfondsen blijkt de geldstroom toe te nemen na een goede prestatie, en ook dat geld zal weer 
een te grote geldstroom richting een hedgefonds

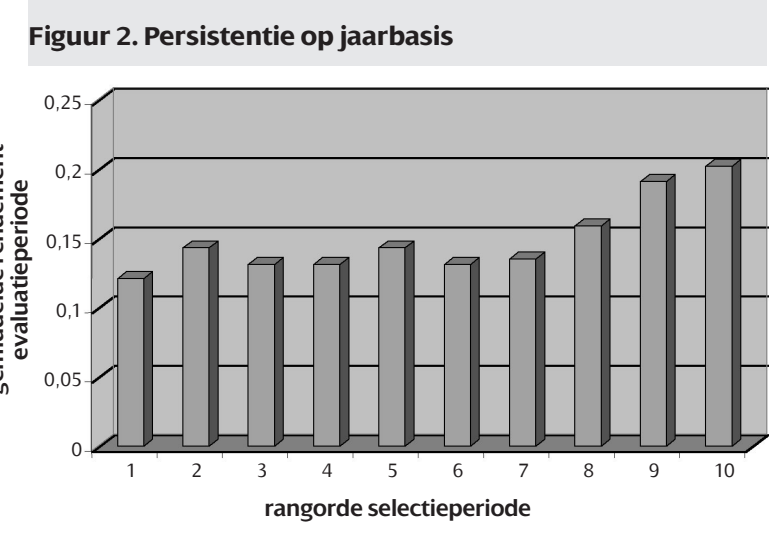

belegd moeten worden volgens de strategie van het fonds. Bij een te grote toestroom zou de winnende strategie van het verleden dan wel eens wat minder succesvol kunnen zijn in de toekomst ${ }^{8}$. Hedgefondsen kunnen simpelweg deze geldstroom afsnijden door van de een op de andere dag geen nieuw geld meer toe te laten. Bovendien kunnen beleggers in hedgefondsen minder snel hun geld liquide maken in verband met de eerder genoemde 'lock-up'-perioden en verplichte aankondigingstermijnen. Dit alles maakt het volgen van een actieve selectiestrategie moeilijker als het om hedgefondsen gaat.

\section{Conclusie}

In de periode 1994-2000 blijkt er bij hedgefondsen duidelijk sprake te zijn van persistentie in prestaties. Dit betekent dat hedgefondsen die in het recente verleden een bovengemiddelde prestatie hebben geleverd, naar verwachting ook in de komende periode weer bovengemiddeld zullen presteren. Op kwartaalbasis zou een zogenaamde winnaars-verliezersstrategie tot een buitengewoon rendement hebben geleid van $12 \%$ (op jaarbasis), terwijl diezelfde strategie op jaarbasis tot een buitengewoon rendement van $8 \%$ zou hebben geleid. Dit zijn opvallende resultaten omdat er bij de traditionele beleggingsfondsen nauwelijks tot geen sprake is van persistentie.

Het waargenomen patroon kan vermoedelijk worden verklaard door de beperkte liquiditeit van hedgefondsen. Zal bij traditionele beleggingsfondsen de persistentie simpelweg worden weggeconcurreerd doordat beleggers actief hun vermogen toewijzen aan de winnende fondsen over een bepaalde periode, bij hedgefondsen zullen diezelfde beleggers worden geconfronteerd met 'lock-up'-perioden waarbij ze hun investering niet liquide kunnen maken gedurende een bepaalde periode. Bovendien kan het zijn dat er bij wordt besloten het fonds te sluiten voor nieuwe beleggers. Naast alle flexibiliteit en andere specifieke kenmerken van hedgefondsen, maakt deze beperkte liquiditeit het hedgefondsmanagers blijkbaar gemakkelijker om hun succesvolle strategie ook in de nabije toekomst nog voort te zetten.

\section{Literatuur}

Agarwal, V. en N.Y. Naik, (2000), Multiperiod Performance Persistence Analysis of Hedge Funds, in: Journal of Financial and Quantitative Analysis, 35, pp. 327-342.

Baquero, G., J. ter Horst en M. Verbeek, (2005), Survival, Look-Ahead Bias and the Persistence in Hedge Fund Performance, in: Journal of Financial and Quantitative Analysis, te verschijnen.

Berk, J.B. en R.C. Green, (2004), Mutual Fund Flows and Performance in Rational Markets, in: Journal of Political Economy, 112, pp. 1269-1295.

Bollen, N.P.B. en J.A. Busse, (2004), Short-term Persistence in Mutual Fund Performance, in: Review of Financial Studies, te verschijnen.

Carhart, M.M., (1997), On Persistence in Mutual Fund Performance, in: Journal of Finance, 52, pp. 57-82.

Horst, J.R. ter, Th.E. Nijman en M. Verbeek, (2001), Eliminating LookAhead Bias in Evaluating Persistence in Mutual Fund Performance, in: Journal of Empirical Finance, 8, pp. 345-373

Sirri, E.R. en P. Tufano, (1998), Costly Search and Mutual Fund Flows, in: Journal of Finance, 53, pp. 1589-1622.

Verbeek, M., (2002), Onweerlegbaar Bewijs? Over het Belang en de Waarde van empirisch Onderzoek voor Financierings- en Beleggingsvraagstukken, Oratie Erasmus Universiteit Rotterdam, 21 juni 2002, https://ep.eur.nl/ handle/1765/343.

\section{Noten}

1 Dit artikel is gebaseerd op een uitgebreid onderzoek naar overlevingseffecten en persistentie in de performance van hedgefondsen, gepubliceerd in Baquero, Ter Horst en Verbeek (2005).

2 Zo biedt Robeco sinds 2,5 jaar Robeco Absolute Return aan, waarin belegd wordt in 21 verschillende hedgefondsen.

3 De TASS database wordt aangeboden door Tremont Capital Management Ltd; zie www.tassresearch.com.

4 Een fonds is 'onder water' als het een negatief geaggregeerd rendement heeft over de meest recente acht kwartalen.

5 Zie Agarwal en Naik (2000).

6 In tegenstelling tot de meer gebruikelijke situatie waarin gewichten exogeen bepaald worden, zijn de gewichten in dit geval endogeen en hebben ze dus wel degelijk effect op de consistentie van de gebruikte schatters.

7 Een mogelijke verklaring voor het positieve persistentiepatroon in gemiddelde rendementen van hedgefondsen vormt de beleggingsstijl van de fondsen. In Baquero, Ter Horst en Verbeek (2005) wordt deze mogelijkheid nader onderzocht, maar ook na correctie voor beleggingsstijl is er nog steeds sprake van een duidelijk en significant patroon.

8 Zie Berk en Green (2004). 